seem to accord well with the statement above (July 3 I) that he had only "just ascertained" the fact to his "great surprise." -ED.]

\section{Subterranean Kaolinisation}

A yeAR ago Mr. John Arthur Phillips, in criticising, before the Geological Society, my theory of kaolinisation as a source of superficial rock temperatures, made a point which is interesting in its bearing upon the composition of derived or secondary lithological products. He endeavoured to ascertain the number of tons of felspathic rock that must be yearly kaolinised in order to supply the quantity of alkalies known to be contained in the mine waters of the Comstock silver lode in Nevada, and in doing so he began with the supposition that in the process of kaolinisation all of the alkali in the felspar goes into solution and is removed. This assumption is undoubtedly incorrect, for even the surface clays which are deposited from running water, and therefore must have been subjected to a maximum leaching, almost invariably contain potassic and sodic salts, as any one may learn by studying the subject of fireclays.

But when the clay is formed by the alteration of rock at great depths, beyond the line of ready drainage and in the presence of a minimum quantity of water, the product is, or may be, quite different from the clay of sedimentary deposition. It is in fact merely the original rock hydrated, and from the example given in the Comstock region the alteration product does not seem to lose much, if any, of its original alkalies. This is demonstrated by the analyses given in Mr. King's Report on the Fortieth Parallel. All the existing analyses of the clays in this region were made on specimens obtained in the first thousand feet of depth, and most of them were taken within 500 feet of the surface. That is, they all come from the region of active drainage, the oxidising and other effects of atmospheric action being well marked in this lode down to the depth of 600 feet. The mean of fouranalyses of clays shows $4 \cdot 72$ of alkalies and $10 \cdot 86$ of water, $\mathrm{CO}_{2}$ and $\mathrm{P}_{2} \mathrm{O}_{5}$. One of the specimens has been very strongly altered, having lost about ro per cent of silica, while another seems to have gained about half as much of the same constituent. As to the composition of the original rocks (propylite and andesite,) it is impossible to be exact, for the alteration in the region has been so extensive and thorough that all attempts to obtain an unaltered specimen have failed. The least altered specimen of propylite from the Virginia range of mountains in which this lode is found contains 5.08 per cent. of alkalies, with I 02 loss by ignition. The most altered specimen contained $5^{\circ} \cdot 26$ per cent. of alkalies, and 6.53 loss by ignition. Andesite showed in the least altered specimen 4.7 alkalies and 2.8 loss; in the most altered specimen 7.37 alkalies and 4.35 loss. It is impossible to compare the clays of this district with unaltered rock from other localities, for the reason that the composition of these eruptive rocks varies strongly, especially in the percentage of alkalies. On the whole I think that any one who will compare the tables of analysis given in vols. i. and iii. of Mr. King's work will be convinced of the truth of what I have asserted above-that subterranean kaolinisation is merely the hydration of a rock in place without other serious alteration. The fact has importance in its relation to the origin of some hydrated aluminous rocks.

Mr. Phillips calculates that the average proportion of alkalies in these rocks is 6.4 per cent., that 813 tons of alkalies are removed yearly in the mine waters, and that "it consequently follows" that the felspar in 12,703 tons of rock "must be annually kaolinised, and the whole of the alkalies removed in solution." It seems to me that a metallurgist of $\mathrm{Mr}$. Phillips' experience should have known that the alkalies are never com. pletely removed in kaolinisation. That he is not acquainted with the peculiar and remarkable conditions of the Comstock is not surprising, for the lode receives but little attention, and that of the most hasty kind, from visitors. I ask your permission to add the following summary of facts which rebut Mr. Phillips' criticism :-

I. The removal of alkalies in subterranean kaolinisation, if it is judged by the existing incomplete series of analyses, seems to vary from less than one-fifth of the quantity of alkalies in the present rock down to almost nothing.

2. The whole results of kaolinisation are not represented in the mine waters, In the vast areas of dry rock alteration has been extensive, and seems to be going on now by means of water-yapour, and none of this action supplies alkalies to the mine waters.

3. The liberation of hot gas which is an accompaniment of kadinisation by atmospheric waters conveys the heat produced in the dry areas to all parts of the mass, and especially to such channels as watercourses and mine-openings.

4. Kaolinisation in the Comstock region is not produced by the action of cold water on cold rock, but by the combination of water and rock, both already heated before the action to very nearly the temperature they attain after it. The heat of the rock is cumulative, its present temperature being mainly the result of ages of previous kaolinisation, the heating effects of which were preserved from dissipation by a blanket of rock $\mathbf{I}, 000$ feet thick. The water which takes part in the action at existing depths of the mine has been heated by its percolation through $\mathrm{I}, 000$ to r, 500 feet of hot rock lying below the blanket spoken of. $\mathbf{M r}$. Phillips calculates that $85^{\circ}$ are added to the temperature, but in fact the actual increment of temperature by kaolinisation is, in the locality given, but a small fraction of this quantity. Considering the small rainfall of Nevada, and the depth at which the waters are now drawn from the rocks, and the perfect correspondence of depth and temperature, it is more probable that the actual gain of heat does not exceed one or two degrees, and may even be less.

5. Mr. Phillips' calculation that 330 tons of water are heated by the kaolinisation of one ton of rock has no foundation in the known facts, but is probably more than 99 per cent. from the truth. His further error in supposing that the increment of heat is $85^{\circ} \mathrm{F}$. instead of being in the neighbourhood of $\mathrm{I}^{\circ}$, as is more probable, relieves his criticism of whatever weight it might have if it had been adjusted to the well-known facts of the case.

II 5, Broadway, New York, June I7 John A. ChuRch

\section{"On a Mode of Explaining the Transverse Vibrations of Light"}

I VENTURE to call attention to what appears to me to be (possibly) an objection to the views advanced by Mr. S. Tolver Preston in his interesting article, "On a Mode of Explaining the Transverse Vibrations of Light" (NATURE, vol. xxi. p. 256). Mr. Preston's hypothesis I understand to be a special modification of Lesage's, the speciality being that the corpuscles which by their impact on the cage-atoms of ordinary matter cause gravitation, are also the carriers of some vector property, the changes in which constitute radiant energy, and that in fact there is no ether except just this assemblage of minute corpuscles co-existing in the ultra-gaseous state (i.e., with a mean free path of great length). Now, as far as I can see, it is a strict corollary from this exceedingly fascinating hypothesis that the velocity of propagation of gravity must be identical with that of light. In other words, the acceleration of a material particle at any instant (I) caused by the attraction of a second particle must be directed to the spot occupied by that second particle, not at the instant I, but at some instant prior to $I$, the interval between the two instants being the time taken by the ultramundane corpuscles, and therefore by light, to travel from the one particle to the other. But do not the observed planetary motions necessitate the assumption that gravity, even if propagated in time at all, is propagated with a velocity vastly in excess of that of light? At any rate this statement is frequently met with in discussions on the nature of gravity, and is much prized by advócates of "action at a distance." If it is true, does it not constitute a fatal objection to Mr. Preston's hypothesis?

Some two years ago it occurred to me that the ether might consist of particles in the ultra-gaseous state, an 1 might thus, in accordance with Lesage's hypothesis, give rise to the mutual gravitation of the grosser atoms immersed in it. I was then unaware of the late Prof. Clerk Maxwell's suggestion that these particles, by being the carriers of some vector property undergoing periodic reversal, might account for the propagation of light; and vaguely hoped that it migbt receive some explanation from the fact, also discovered by Clerk Maxwell, that a body in the ultra-gaseous state behaves like a solid towards any confining boundaries to the extent that, like a solid, it opposes a certain resistance to change of shape. But I deemed the whole theory to labour under the fatal objection of not giving a sufficient velocity of propagation to gravity.

I write in the hope that $\mathrm{Mr}$. Preston or another of your readers will inform me whether my objection is a valid one.

$$
\text { J. W. FRANKLAND }
$$

